EDITORIAL

\title{
LA VIDA DEL ARTÍCULO COMIENZA CON SU PUBLICACIÓN
}

\section{The life of the paper begins with its publication}

José Luis PARDAL-REFOYO

Director de Revista ORL. Ediciones Universidad de Salamanca. Hospital Universitario de Salamanca. Servicio de Otorrinolarinología y Cirugía de Cabeza y Cuello. Salamanca. España

Correspondencia: jlpardal@usal.es

Fecha de recepción:

Fecha de aceptación:

Fecha de publicación: 28 de abril de 2019

Fecha de publicación del fascículo: 1 de junio de 2019

Conflicto de intereses: Los autores declaran no tener conflictos de intereses

Imágenes: Los autores declaran haber obtenido las imágenes con el permiso de los pacientes

Política de derechos y autoarchivo: se permite el autoarchivo de la versión post-print (SHERPA/RoMEO)

Licencia CC BY-NC-ND. Licencia Creative Commons Atribución-NoComercial-SinDerivar 4.0 Internacional

Universidad de Salamanca. Su comercialización está sujeta al permiso del editor

Si hay calificativos que definan la situación actual del modelo de la información sobrevenida con los sistemas masivos de comunicación son la volatilidad y la obsolescencia, no solamente porque los contenidos desaparecen de la mente de los lectores con la misma rapidez con la que nacen sino porque los contenidos y las formas quedan anticuadas tan pronto se hacen públicos.

Luchar contra ambos es uno de los objetivos de la publicidad: mantener el producto vivo en la mente de los clientes.

Estos principios son aplicables al artículo científico. Durante años el objetivo final del científico era publicar su artículo y el propio soporte de la publicación (la revista) y sus redes de distribución eran garantía de permanencia. Esto hoy, en parte, ya no es así. El aumento de la producción científica y de los canales de difusión hacen que fácilmente un artículo pase al olvido tan pronto nace en la revista, incluso en publicaciones con mayor índice de impacto -tema sobre el que se debate mucho y hay mucho que aclarar-. Las revistas tienen sus cauces para conseguir la visibilidad de sus contenidos a través de bases de datos y redes informativas.

Los lectores e investigadores buscan y localizan la información que desean a través de esas base de datos, sin embargo, el artículo adquiere valor añadido si está presente en la mente del grupo diana (investigadores, publicistas, lectores) independientemente del soporte o título de la publicación en la que nace. Dicho de otra forma, los autores tienen una gran responsabilidad en la difusión de sus productos a través de las redes de comunicación e información. 


\section{LA VIDA DEL ARTÍCULO COMIENZA CON SU PUBLICACIÓN PARDAL-REFOYO JL}

Hace años la difusión de la información se realizaba a través de la revista que en papel llegaba a los lectores bien físicamente o a las bibliotecas y a través de los autores en congresos o conferencias. Así la información se transmitía preferentemente a grupos de investigadores con similares intereses. Posteriormente las listas de difusión por correo electrónico revolucionaron la forma en que los investigadores transmitían sus artículos.

Actualmente a estos medios de difusión, que podemos considerar clásicos, se unen las redes sociales. Por una parte, las redes sociales generales (horizontales como Facebook, Twitter, Instagram, Google+, etc.) o las verticales según el grupo de interés, como las redes profesionales (ResearchGate, Linkedin, Mendeley, Academia.edu, ScienceBook, Scholabrate, etc.). Además de los registros de los perfiles de investigadores que se comportan como una red social (ORCID, ResearchID, ScopusID, Currículum Vitae Normalizado CVN).

Parece que en este mundo de información volátil y obsolescente es importante la actividad del autor como difusor de su actividad científica que conducirá a una mayor visibilidad $y$, ocasionalmente, puede que a mayor número de citaciones. Aludiendo a uno de nuestros mejores divulgadores científicos: La participación activa en Twitter es un poderoso medio para promocionar y difundir la producción académica (Francis Villatoro, 2019).

Por tanto, recomendamos a los autores a promocionar sus artículos, que nacen en una revista científica, a través de las redes sociales generales y científicas para una mayor visibilidad de su producción científica.

\section{REFERENCIAS}

Ferreras Fernández T, Merlo Vega JA. Repositorios de acceso abierto: un nuevo modelo de comunicación científica. La Revista de la Sociedad ORL CLCR en el repositorio Gredos. Rev Soc Otorrinolaringol Castilla Leon Cantab La Rioja. 2015 May. 6 (12): 94-113. http://hdl.handle.net/10366/125467

Ferreras-Fernández T. Revista ORL en el Ecosistema de la Ciencia Abierta. Revista ORL [Internet]. 1 Jun 2018 [citado 28 Abr 2019]; 9(6): 1.7. Disponible en: http://revistas.usal.es/index.php/2444-7986/ article/view/18330

Ferreras-Fernández T. Revista ORL en el Ecosistema de la Ciencia Abierta. Revista ORL [Internet]. 1 Dic 2018 [citado 28 Abr 2019]; 9(4): 273-282. Disponible en: http://revistas.usal.es/index.php/2444-7986/ article/view/18874

Martín-Rodero H. ORCID: sistema de identificación unívoca de autores. Revista ORL [Internet]. 3 Mar 2016 [citado 28 Abr 2019]; 7(2): 73-75. Disponible en: http://revistas.usal.es/index.php/2444-7986/ article/view/13998

Martín-Rodero H. Revistas de Otorrinolaringología (ORL): impacto y visibilidad. Revista ORL [Internet]. 22 Jul 2016 [citado 28 Abr 2019]; 7(3): 133-136. Disponible en: http://revistas.usal.es/ index.php/2444-7986/article/view/14912

Muñoz-Martín B. Descriptores y palabras clave. Revista ORL, 7 (2016). http://hdl.handle. net/10366/130606

Muñoz-Martín B. Incrementa el impacto de tus artículos y blogs: de la invisibilidad a la visibilidad. Rev Soc Otorrinolaringol Castilla Leon Cantab La Rioja. 2015 Nov. 6 (Supl. 4): S6-S32. http://hdl. handle.net/10366/126907

Pardal-Refoyo JL, Azofra Agustín E, Ferreras Fernández T, Martín Rodero H, Redero Hernández Á. Nuevas vías de publicación para revistas biomédicas. El proyecto de Revista ORL de Ediciones Universidad de Salamanca. http://hdl.handle. net/10366/138568. En Merlo Vega, J. A. (Ed.). (2018). Ecosistemas del Acceso Abierto. Salamanca: Ediciones Universidad de Salamanca. Aquilafuente;228. http://hdl.handle.net/10366/138566

Revista ORL en Amazon. Impresión bajo demanda

Revista ORL. @RevistaORL en https://twitter.com/ RevistaORL

Revista ORL. @revistaorl en https://www.facebook. com/revistaorl/

Revista ORL. www.revistaorl.com

Social Media en Investigación. https://socialmediaeninvestigacion.com/

Villatoro, FR. La influencia de Twitter sobre el impacto de tus artículos científicos. En: La ciencia de la Mula Francis. El blog de Francisco R Villatoro. Entrada de 22 abril, 2019. https:// francis.naukas.com/2019/04/22/la-influenciade-twitter-sobre-el-impacto-de-tus-articuloscientificos/?platform=hootsuite 